\title{
PRAME expression and promoter hypomethylation in epithelial ovarian cancer
}

\author{
Wa Zhang ${ }^{1,10}$, Carter J. Barger ${ }^{1}$, Kevin H. Eng ${ }^{4}$, David Klinkebiel ${ }^{2}$, Petra A. Link ${ }^{3}$, \\ Angela Omilian ${ }^{5}$, Wiam Bshara ${ }^{5}$, Kunle Odunsi ${ }^{6,7,8}$, Adam R. Karpf ${ }^{1,9}$ \\ ${ }^{1}$ Eppley Institute for Cancer Research, University of Nebraska Medical Center, Omaha, NE, USA \\ ${ }^{2}$ Department of Biochemistry and Molecular Biology, University of Nebraska Medical Center, Omaha, NE, USA \\ ${ }^{3}$ Department of Pharmacology, Roswell Park Cancer Institute, Buffalo, NY, USA \\ ${ }^{4}$ Department of Biostatistics and Bioinformatics, Roswell Park Cancer Institute, Buffalo, NY, USA \\ ${ }^{5}$ Department of Pathology, Roswell Park Cancer Institute, Buffalo, NY, USA \\ ${ }^{6}$ Department of Gynecologic Oncology, Roswell Park Cancer Institute, Buffalo, NY, USA \\ ${ }^{7}$ Department of Immunology, Roswell Park Cancer Institute, Buffalo, NY, USA \\ ${ }^{8}$ Center for Immunotherapy, Roswell Park Cancer Institute, Buffalo, NY, USA \\ ${ }^{9}$ Fred and Pamela Buffett Cancer Center, University of Nebraska Medical Center, Omaha, NE, USA \\ ${ }^{10}$ Current address: Wilmer Eye Institute, Johns Hopkins University School of Medicine, MD, USA
}

Correspondence to: Adam R. Karpf, email: adam.karpf@unmc.edu

Keywords: PRAME, cancer testis antigens, epithelial ovarian cancer, high grade serous cancer, DNA methylation

Received: May 02, $2016 \quad$ Accepted: May 29, $2016 \quad$ Published: June 13, 2016

\section{ABSTRACT}

PRAME is a cancer-testis antigen (CTA) and potential immuno-therapeutic target, but has not been well-studied in epithelial ovarian cancer (EOC) or its high grade serous (HGSC) subtype. Compared to normal ovary, PRAME expression was significantly increased most EOC, regardless of stage and grade. Interestingly, PRAME mRNA expression was associated with improved survival in the HGSC subtype. The PRAME locus was a frequent target for copy number alterations (CNA) in HGSC but most changes were heterozygous losses, indicating that elevated PRAME expression is not typically due to CNA. In contrast, PRAME promoter DNA hypomethylation was very common in EOC and HGSC and correlated with increased PRAME expression. PRAME expression and promoter hypomethylation both correlated with LINE-1 hypomethylation, a biomarker of global DNA hypomethylation. Pharmacologic or genetic disruption of DNA methyltransferase (DNMT) enzymes activated PRAME expression in EOC cells. Immunohistochemistry (IHC) of PRAME in EOC revealed frequent, but low level, protein expression, and expression was confined to epithelial cells and localized to the cytoplasm. Cytoplasmic PRAME expression was positively associated with PRAME mRNA expression and negatively associated with promoter methylation, but the latter correlation was not statistically significant. PRAME protein expression did not correlate with EOC clinicopathology or survival. In summary, PRAME is frequently expressed in EOC at the MRNA and protein levels, and DNA methylation is a key mechanism regulating its expression. These data support PRAME as an immunotherapy target in EOC, and suggest treatment with DNMT inhibitors as a means to augment PRAME immunotherapy.

\section{INTRODUCTION}

Ovarian cancer is the seventh most common female cancer worldwide and accounts for the fifth most female cancer deaths in the US $[1,2]$. Approximately $90 \%$ of ovarian cancer cases are epithelial (EOC) [3]. More than $60 \%$ of EOC are diagnosed with advanced disease, and the five-year survival for these women is $<30 \%$ [2]. High grade serous cancer (HGSC) is the most common EOC subtype, accounting for $\sim 70 \%$ of cases. HGSC is often 
clinically-advanced (stage $3+$ ), is high grade (grade $2+$ ), and is associated with poor survival [4]. Recent largescale genomic studies have shed light on the molecular mechanisms of HGSC $[4,5]$. Continued investigations are needed to facilitate improved diagnostic and therapeutic approaches.

PRAME (preferentially expressed antigen in melanoma; a.k.a. MAPE, OIP4, CT130) was identified as a gene encoding an HLA-A24-restricted peptide that stimulated tumor-specific cytotoxic T lymphocytes in a human melanoma cell line [6]. PRAME is located on chromosome 22q11.22 and encodes a 509 amino acid protein [7]. PRAME is an autosomal cancer-testis antigen (CTA) gene, based on its chromosomal location, expression profile, and immunogenicity. PRAME is not commonly expressed in normal adult somatic tissues, with the exception of testis [6], but is expressed in many cancers, and is immunogenic [8-10]. PRAME is expressed in both solid tumors and leukemia, making it an attractive potential immunotherapy target [11]. Similar to other CTAs PRAME has been reported to be epigenetically regulated by DNA methylation $[12,13]$. Promoter hypomethylation of PRAME was reported in AML and $\operatorname{MDS}[14,15]$. In addition, the DNA methyltransferase inhibitor (DNMTi) 5-aza2'-deoxycytidine (decitabine) induced PRAME expression in cancer cell lines [16-20]. Importantly, decitabine can also stimulate PRAME-specific immunereactivity, suggesting an approach to augment PRAME immunotherapy, similar to our strategy for the X-linked CTA NY-ESO-1 [20-23].

In addition to its expression in cancer and immunogenicity, PRAME is of interest based on a possible contribution to oncogenesis. PRAME was reported to be a ligand-dependent RAR corepressor and inhibitor of retinoic acid (RA) signaling [24]. PRAME expressing leukemia cells were growth inhibited in a dose-dependent fashion by all trans retinoic acid (ATRA), suggesting a therapeutic approach for tumors that express PRAME [8, 25]. More recent studies have additionally linked PRAME to chemotherapy sensitivity and apoptosis [26-28]. PRAME expression has also been reported to be associated with prognosis, although this has been an inconsistent observation [27, 29-32].

In EOC, PRAME has not been well-studied, but initial reports indicate that it is expressed and may be associated with survival [32-35]. PRAME mRNA and protein expression in EOC were reported to correlate $[32,35]$, suggesting the importance of transcriptional regulation for PRAME expression in EOC. No information has been provided regarding the genetic or epigenetic mechanisms that account for PRAME expression in EOC. Also, the relationship between PRAME and the status of the RA pathway in EOC is unknown. Here we address these and other important gaps in our knowledge regarding PRAME in EOC and HGSC.

\section{RESULTS}

\section{$P R A M E$ mRNA expression in EOC}

We measured PRAME expression using RT-qPCR in a set of primary EOC $(n=119)$ and normal ovary (NO; $n=17$ ) samples collected at Roswell Park Cancer Institute (RPCI; see Methods). PRAME was overexpressed in a majority of $(\sim 60 \%)$ of primary EOC as compared to NO (Figure 1A). PRAME mRNA was significantly increased expression both in serous and non-serous histology EOC (Figure 1B). PRAME was also significantly increased in both early (I/II) and advanced (III/IV) stage EOC, and in both grade 2 and grade 3 EOC (Figure 1C-1D).

\section{PRAME mRNA expression and HGSC survival}

Analysis of our EOC data did not reveal a significant association of PRAME mRNA expression with patient survival (data not shown). However, we had a limited number of patients evaluable for survival, and our samples were heterogeneous with regards to EOC histological subtype, which complicates survival analysis. Thus, we used data from The Cancer Genome Atlas (TCGA) [4]. TCGA includes only HGSC, and contains a large number of patients evaluable for survival. Restricting survival analysis to HGSC also largely mitigates the influence of disease progression, as the vast majority HGSC cases are clinically-advanced. We used three sources of mRNA expression data from TCGA, Affymetrix microarray $(N=576)$, Agilent microarray $(N=561)$, and RNAseq $(N=307)$, which we independently tested for survival associations. Using Affymetrix data, PRAME expression correlated with improved overall and disease-free (a.k.a. progression-free) survival (OS; DFS) (Figure 2). Similar results were obtained using Agilent data (OS, $p=0.036$; DFS, $p=0.118)$. RNAseq data displayed a trend toward improved survival with increased $P R A M E$, but this did not reach statistical significance (OS, $p=0.196$; DFS, $p=0.694)$. The reason for the distinct results between microarray and RNAseq is unknown, but could relate to the number of samples analyzed.

\section{$P R A M E$ genomic copy number alterations in HGSC}

To define the mechanisms underlying increased PRAME expression, we examined copy number alterations (CNA) using cBioPortal analysis of TCGA data [36, 37]. CNA are the predominant molecular alteration in HGSC and are associated with altered gene expression [4, 38, 39]. The chromosomal location of PRAME is 22q11.22. Amongst all tumor types with TCGA data, PRAME was most frequently amplified in HGSC (Figure 3A). However, the proportion of HGSC with PRAME amplification was relatively low $(<4.0 \%)$ as compared to the high prevalence of increased PRAME expression (Figure 3A; Figure 1). 
Interestingly, most HGSC cases show PRAME CNA, but the majority of these are heterozygous losses (63\%), while copy number gains + amplifications are far less frequent (16\%) (Figure 3B). PRAME expression significantly correlated with genomic copy number using RNAseq data, and showed borderline significance using microarray data (Figure 3C-3D). Based on the relationship between PRAME mRNA expression and survival as described above, we tested whether PRAME copy number correlated with HGSC survival. However, PRAME copy number (gains + amplifications vs. all other copy number states) did not correlate with HGSC survival (data not shown). Together, these data indicate that copy number influences PRAME expression in HGSC, but suggests that additional mechanisms are more likely to account for the increased expression of PRAME commonly observed in this disease.

\section{$P R A M E$ promoter region DNA methylation in EOC}

Promoter DNA methylation has been shown to regulate the expression of both $\mathrm{X}$-linked and autosomal CTA genes in EOC [13, 40-42]. To examine whether $P R A M E$ is regulated by DNA methylation in EOC, we first examined the PRAME gene structure and observed that the $5^{\prime}$ region of $P R A M E$, which overlaps the promoter and $5^{\prime}$ untranslated region (UTR), contains a CpG island [43] located downstream of the transcriptional start site (TSS) (Figure 4A, top). To determine if promoter methylation correlates with PRAME expression in EOC, we conducted bisulfite clonal sequencing to survey three areas of the $5^{\prime}$ region of PRAME in normal controls and EOC (Figure 4A). We analyzed methylation of four sample
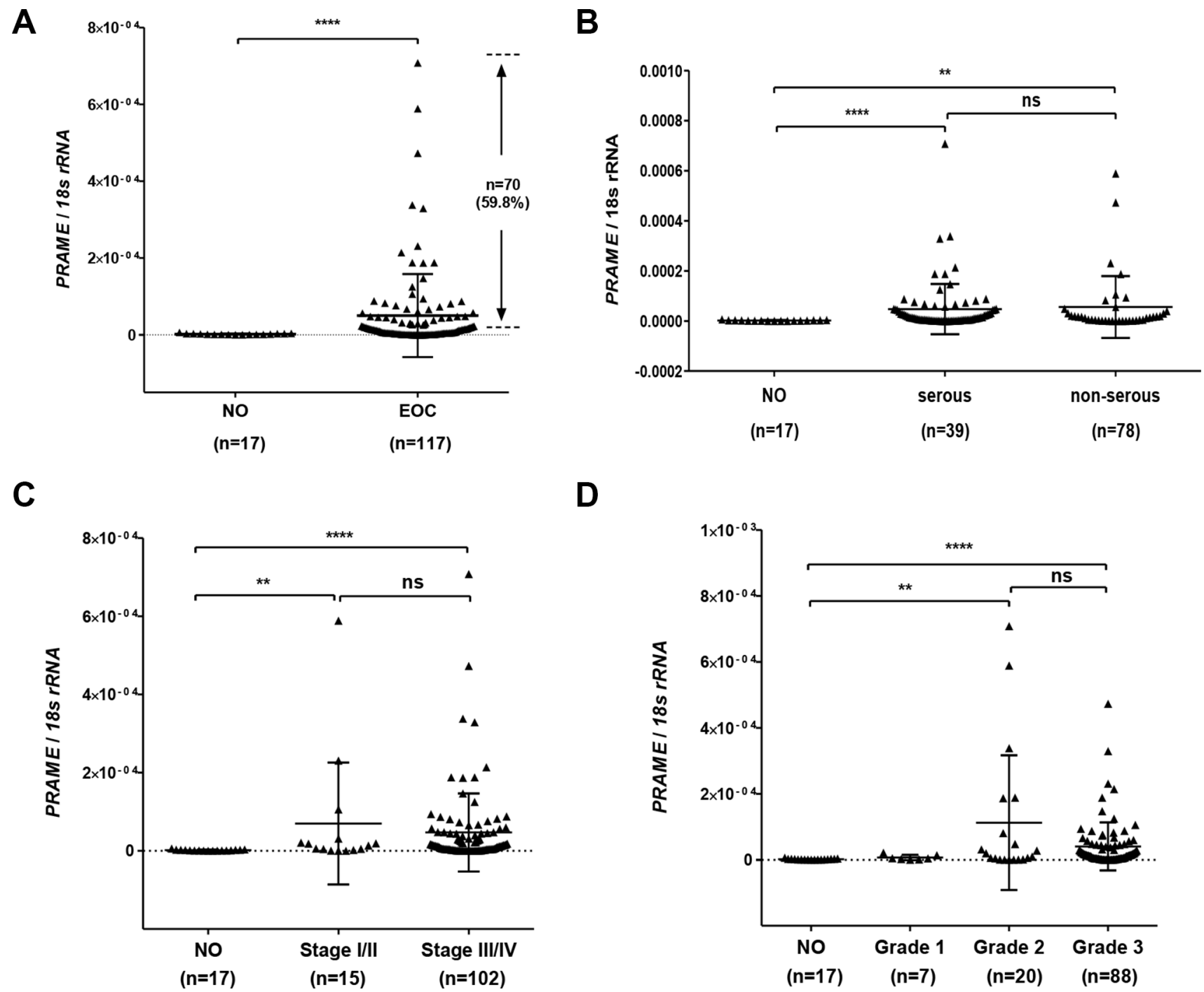

D

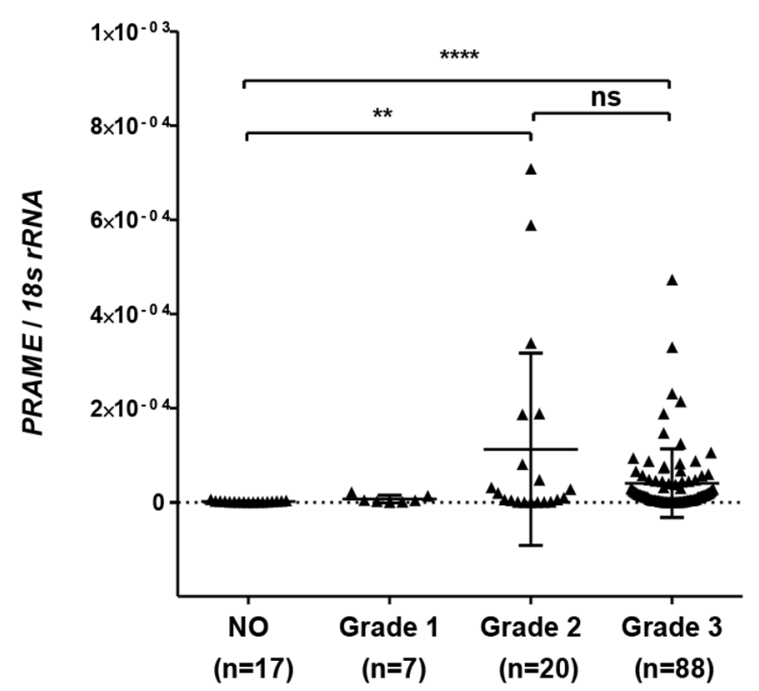

Figure 1: $\boldsymbol{P R} \boldsymbol{A M E} \mathbf{m R N A}$ expression in EOC. PRAME mRNA expression was measured by RT-qPCR and normalized to $18 s+R N A$. (A) PRAME in normal ovary (NO) and EOC. The proportion of EOC with elevated PRAME mRNA expression as compared to NO is indicated. (B) PRAME in NO, serous histology EOC, and other histology EOC. (C) PRAME expression and EOC clinical stage, separated into Stage I/II and Stage III/IV. (D) PRAME expression and EOC histological grade. The two-tailed Mann-Whitney test $p$-value is indicated $(* * P<0.01 ; * * * * P<0.0001 ;$ ns: not significant). 
groups: 1) normal fallopian tube epithelium (FTE), 2) normal ovarian surface epithelium (OSE), 3) EOC sample pool $(n=3)$ with low PRAME expression and 4) EOC sample pool $(n=3)$ with high PRAME expression. Notably, PRAME methylation was significantly reduced throughout the $5^{\prime}$ region in EOC tumors expressing high levels of $P R A M E$, as compared to the normal controls or to EOC showing low PRAME expression (Figure 4A-4B).

Bisulfite clonal sequencing is a low-throughput assay poorly suited for interrogation of large numbers of samples. To determine PRAME methylation levels in a large group of normal and tumor samples, we used quantitative bisulfite pyrosequencing [44]. We measured methylation at three $\mathrm{CpG}$ sites that showed a clear association with PRAME expression in bisulfite clonal sequencing data (Figure 4A; boxed area within Region 3 ). Figure $5 \mathrm{~A}$ shows the results of this analysis, which revealed frequent and significant hypomethylation of $P R A M E$ in EOC as compared to OSE or FTE. Importantly, PRAME methylation was inversely correlated with PRAME expression (Figure 5B). As an additional test of this

A HGSC OS vS. PRAME

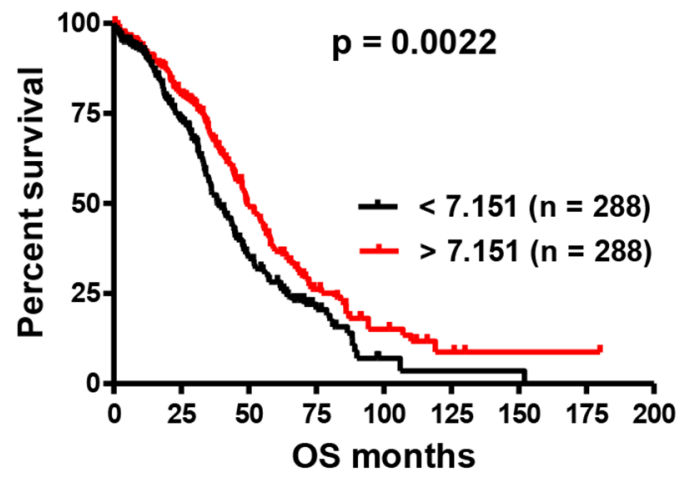

C

HGSC OS vs. PRAME

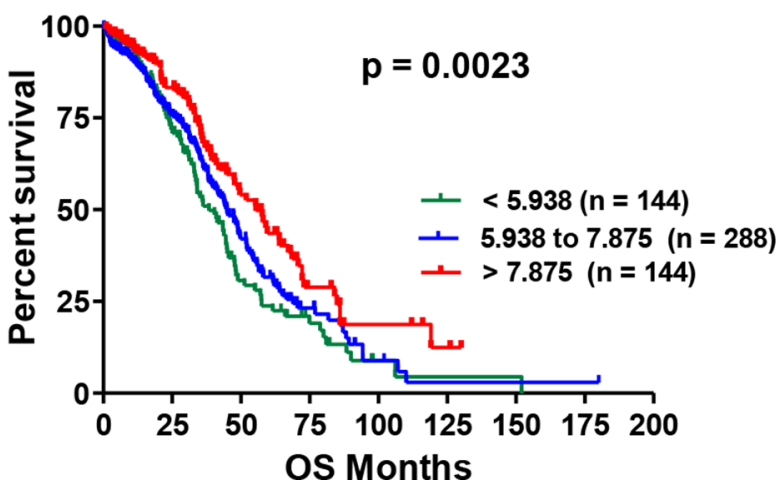

association, we obtained an independent set of data from a recent study of HGSC in which PRAME methylation was determined using Illumina $450 \mathrm{~K}$ bead arrays [5]. The stars in Figure 4A (top) indicate the 11 sites of overlap between bisulfite clonal sequencing data and $450 \mathrm{~K}$ data ( 3 additional sites measured by $450 \mathrm{~K}$ are located further upstream). This analysis confirmed an indirect relationship between PRAME expression and methylation (Figure 5C). We additionally observed that $P R A M E$ was significantly hypomethylated in EOC in both early and late stages, in grades 2 and 3 disease, and in tumors with both serous and non-serous histology (Figure 6). We did not observe an association between $P R A M E$ promoter methylation and OS or DFS (data not shown).

\section{$P R A M E$ promoter methylation, $P R A M E$ mRNA expression, and $L I N E-1$ methylation}

For several CTA genes, promoter hypomethylation and expression are connected to an epigenetic alteration known as global DNA hypomethylation, a

B

HGSC DFS vS. PRAME

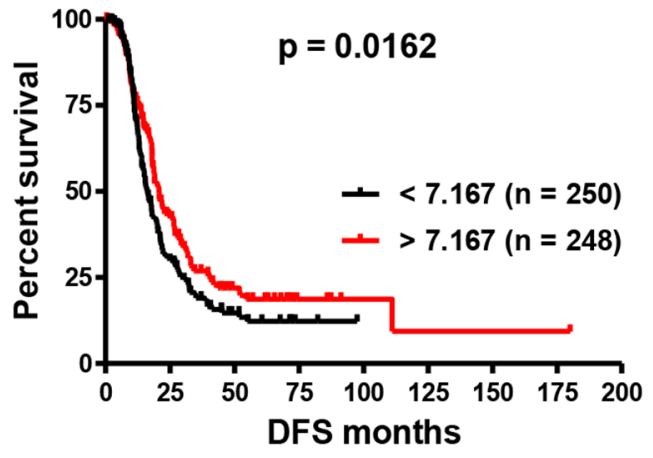

D

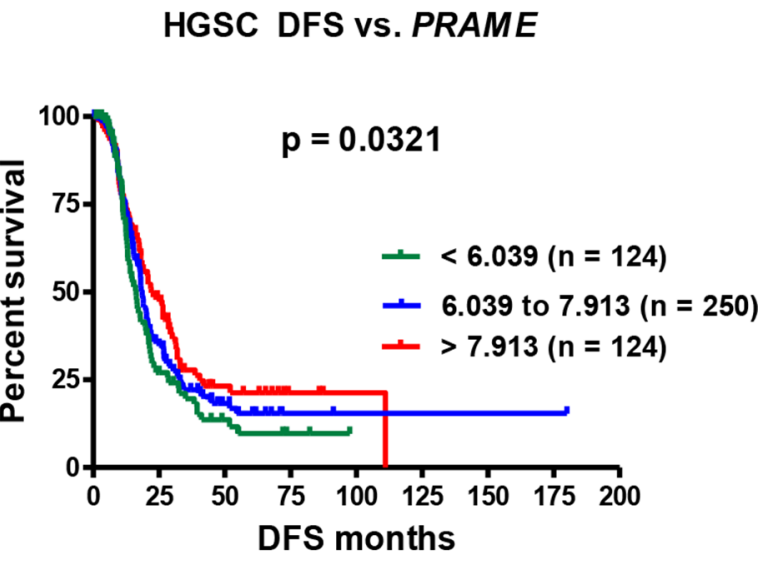

Figure 2: PRAME mRNA expression and HGSC patient survival. (A) Overall survival (OS) and (B) Disease-free survival (DFS) of HGSC patients vs. PRAME expression, dichotomized at the median expression value. (C) OS and (D) DFS of HGSC patients vs. PRAME expression tertiles. PRAME expression was measured by Affymetrix U133 microarray; data were obtained for TCGA HGSC from cBioPortal. Logrank test $p$-values for two group comparison (A-B) or three-group trends (C-D) are shown. 
cancer phenotype associated with hypomethylation at repetitive DNA elements [12, 41, 45]. Thus, CTA gene promoters and repetitive elements, both of which are hypermethylated in normal tissues, can become hypomethylated in concert in cancer. To address whether $P R A M E$ is linked to this phenomenon, we measured
LINE-1 methylation, a surrogate for global methylation status [41], and performed correlation analyses of LINE1 methylation with PRAME methylation and mRNA expression. Notably, LINE-1 methylation correlated directly with $P R A M E$ promoter methylation and indirectly with $P R A M E$ expression (Figure 7A-7B). Thus, PRAME

A

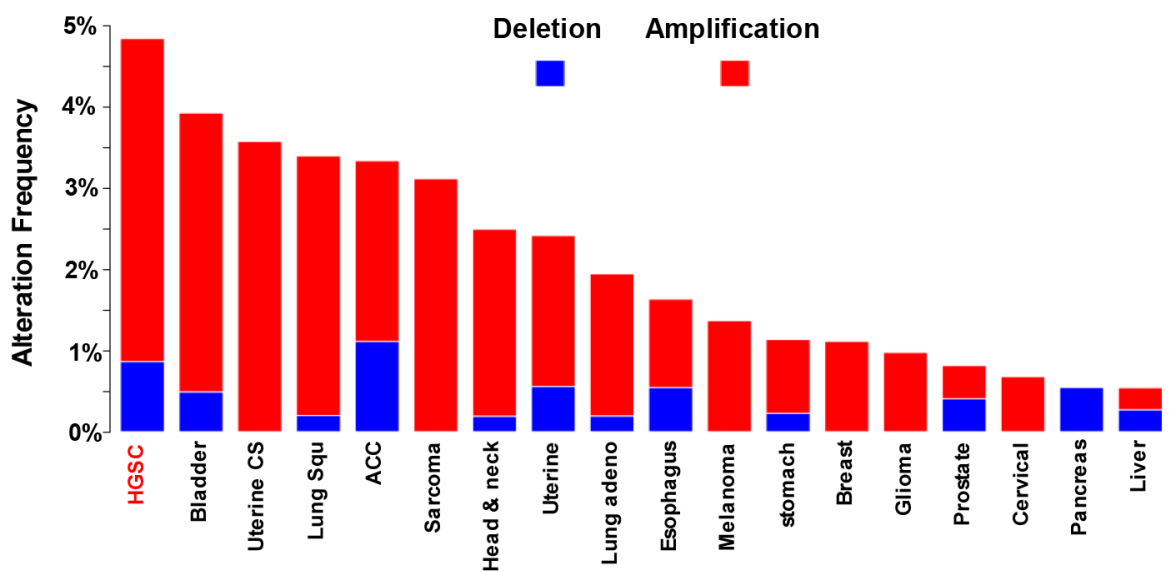

B PRAME copy number: altered in $458 / 579(79 \%)$ of HGSC

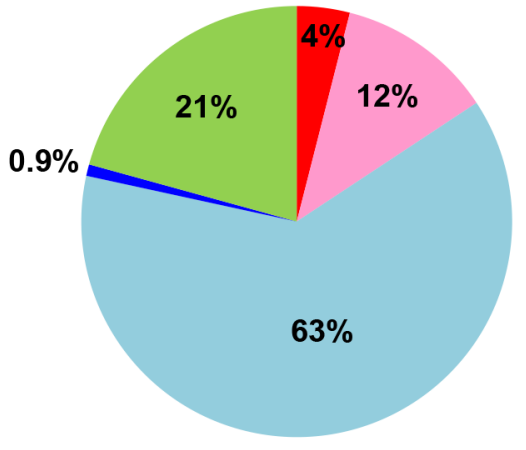

Total $\mathrm{n}=\mathbf{5 7 9}$

- Amplification $(\mathrm{n}=\mathbf{2 3})$

Gain ( $n=68)$

Heterozygous loss $(n=363)$

- Homozygous deletion $(n=5)$

$\square$ Unaltered (Diploid) $(n=120)$

C

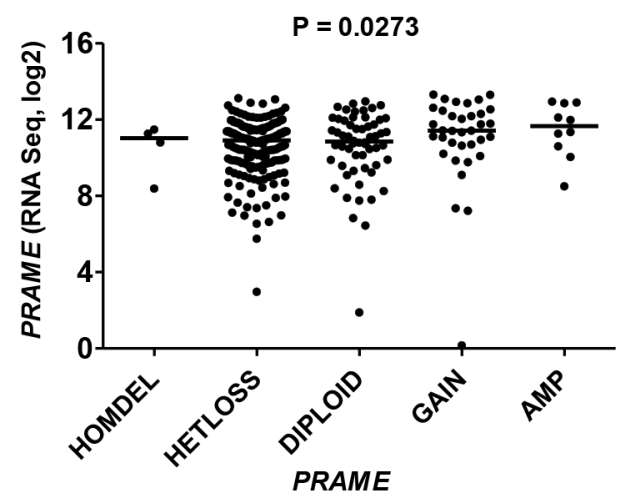

(GISTIC putative copy-number)
D

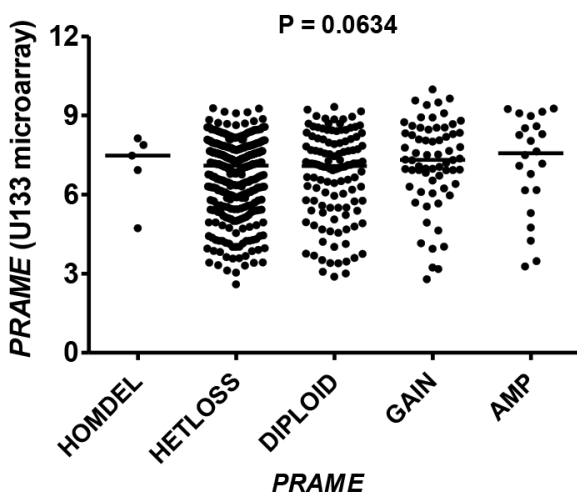

(GISTIC putative copy-number)

Figure 3: PRAME copy number and mRNA expression in HGSC. TCGA data were obtained from cBioPortal [36]. (A) PRAME CNA (deletions-blue; amplifications-red) in different TCGA tumor types. The PRAME locus is at 22q11.22. (B) PRAME copy number data for HGSC $(n=579)$. (C) PRAME mRNA expression (RNAseq) and PRAME copy number in HGSC $(N=300)$. (D) PRAME mRNA expression (Affymetrix U133 microarray) and PRAME copy number in HGSC $(N=556)$. In C-D, Kruskal-Wallace $p$-values are shown. 
A

CGI: 312 bp, $\% G C=66$, Obs/Exp CpG = 0.76
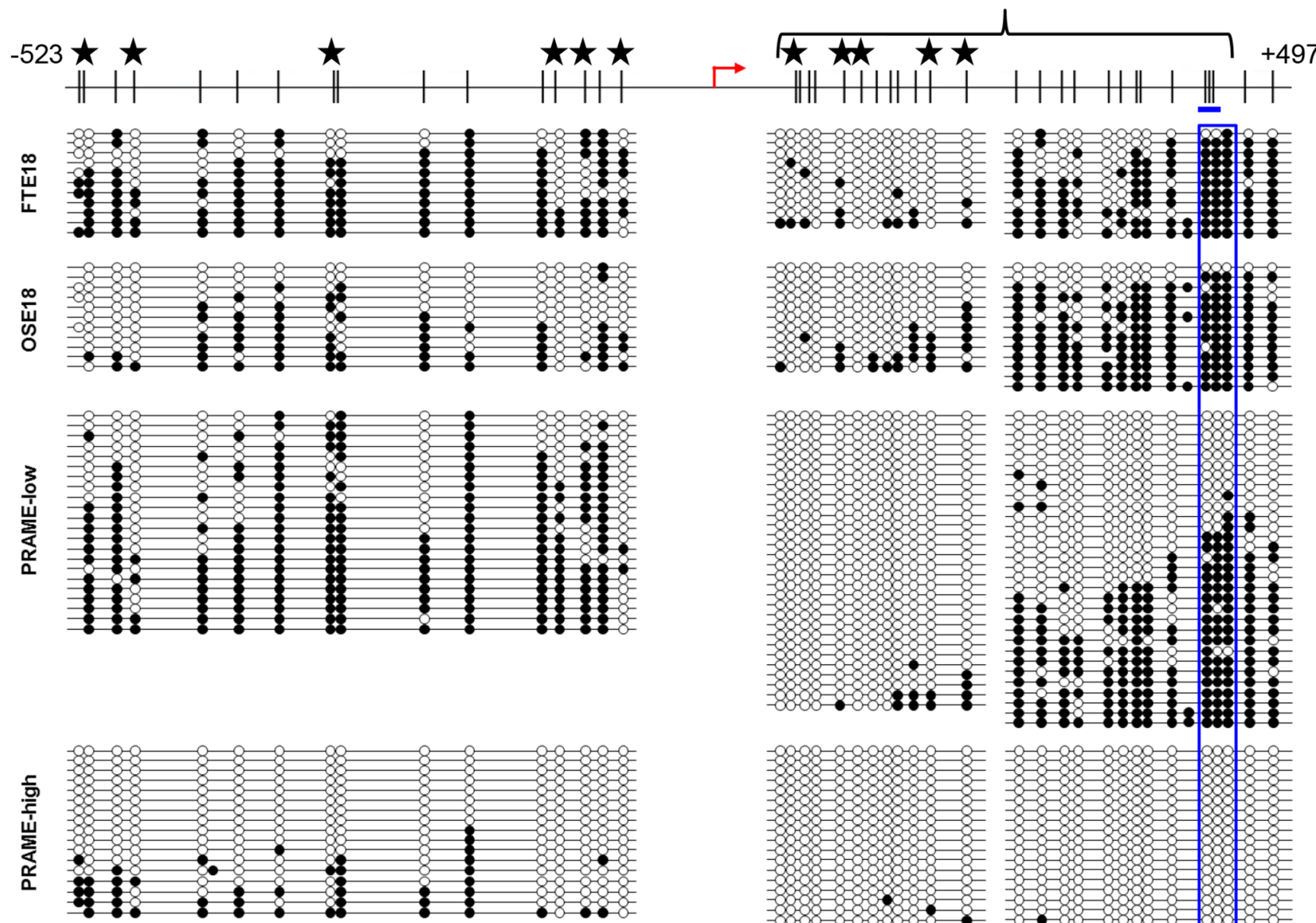

Region 1
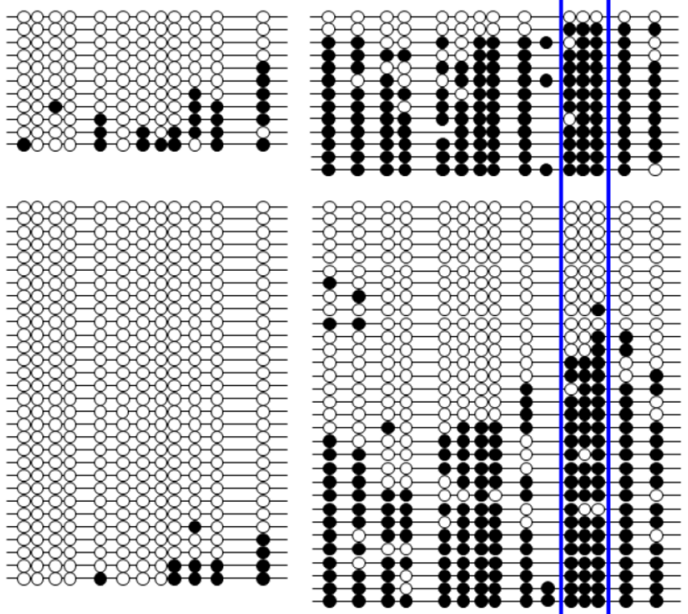

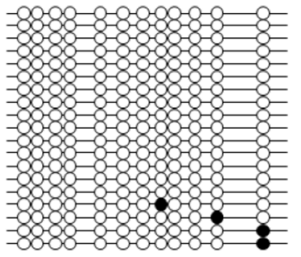

Region 2

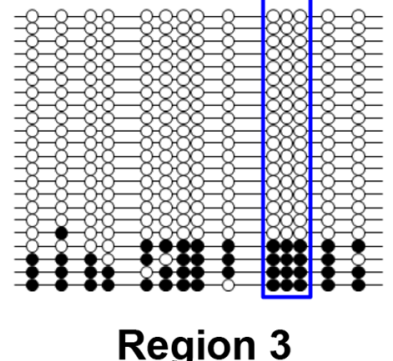

B

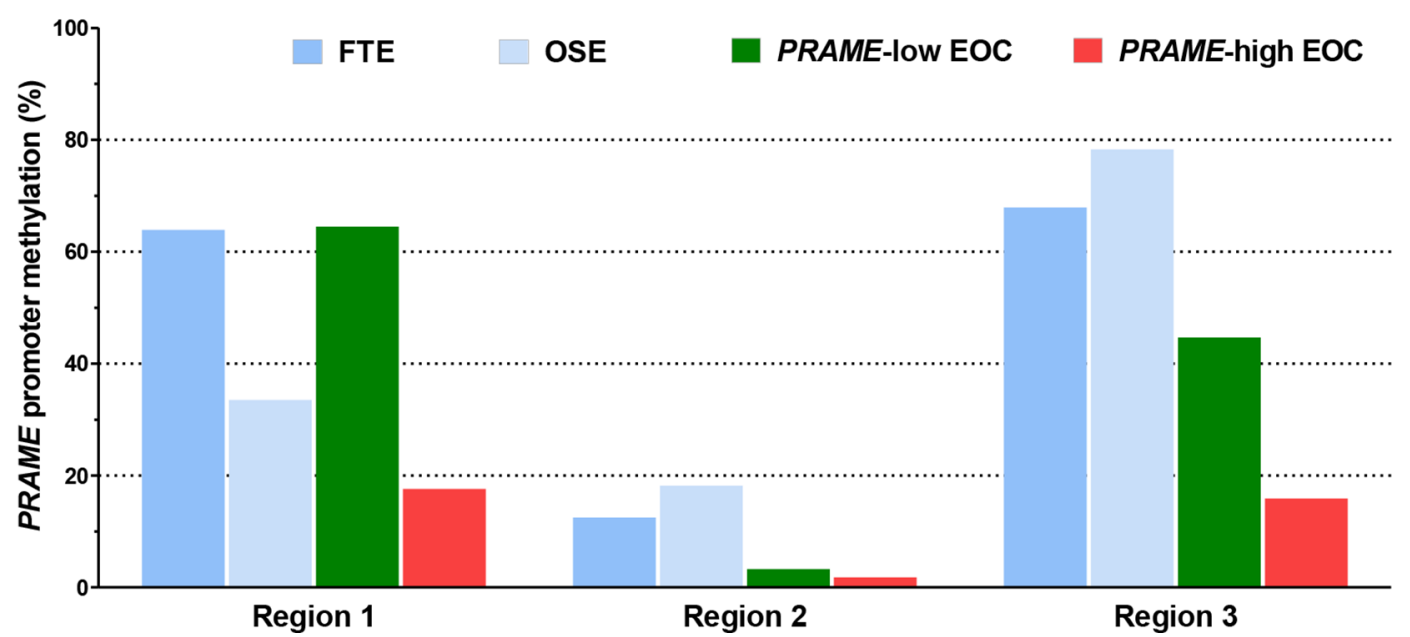

Figure 4: Sodium bisulfite clonal sequencing of the PRAME 5' region. (A) Top: diagram of the PRAME promoter and 5'UTR region, including $\mathrm{CpG}$ sites (black hash marks), NCBI-predicted TSS (red broken arrow), and region analyzed by pyrosequencing (blue rectangle). Stars indicate overlapping $\mathrm{CpG}$ analyzed by Illumina $450 \mathrm{~K}$ bead arrays (see Figure 5C). Bottom: bisulfite clonal sequencing data for three consecutive regions of the PRAME $5^{\prime}$ region. Filled and open circles indicate methylated and unmethylated CpGs, and each row represents one sequenced allele. Data are shown for FTE, OSE, a pool of three EOC samples with low PRAME expression, and a pool of three EOCs with high PRAME expression. (B) Graphical summary of data presented in (A). 
fits within the paradigm previously observed for other $\mathrm{X}$-linked and autosomal CTA genes [41].

\section{Pharmacological or genetic inhibition of DNMTs induces $P R A M E$ expression}

To test whether DNA methylation functionally represses PRAME expression, we used decitabine treatment [46]. We treated SV40 large $\mathrm{T}$ antigenimmortalized OSE cells (IOSE121) and four EOC cell lines (OVCAR3, OVSAHO, A2780, SNU119). Decitabine treatment significantly induced PRAME expression in IOSE121, OVCAR3, and OVSHAO, which showed low baseline PRAME expression. In contrast, decitabine did not induce PRAME in A2780 or SNU119, which showed high baseline PRAME expression (Figure 8A). To confirm that decitabine induced hypomethylation, we conducted bisulfite clonal sequencing of IOSE121 cells and observed hypomethylation, as expected (Figure 8B). In addition, bisulfite sequencing revealed that PRAME was hypomethylated at baseline in the two cell lines with high basal PRAME expression, A2780 and SNU119 (Figure $8 \mathrm{~B})$. To confirm a functional link between DNMTs and PRAME expression, we measured PRAME in the HCT116 DNMT somatic cell knockout system [47]. Cells with dual knockout of DNMT1 and DNMT3b, but not either enzyme alone, leads to global DNA hypomethylation in these cells $[47,48]$. Notably, dual DNMT knockout cells showed elevated PRAME expression (Figure $8 \mathrm{C}$ ).

\section{PRAME protein expression in EOC}

We used IHC of EOC tissue microarrays (TMA) to measure PRAME protein expression $(N=244)$ and to test its association with PRAME mRNA expression, $P R A M E$ promoter methylation, and clinicopathology.

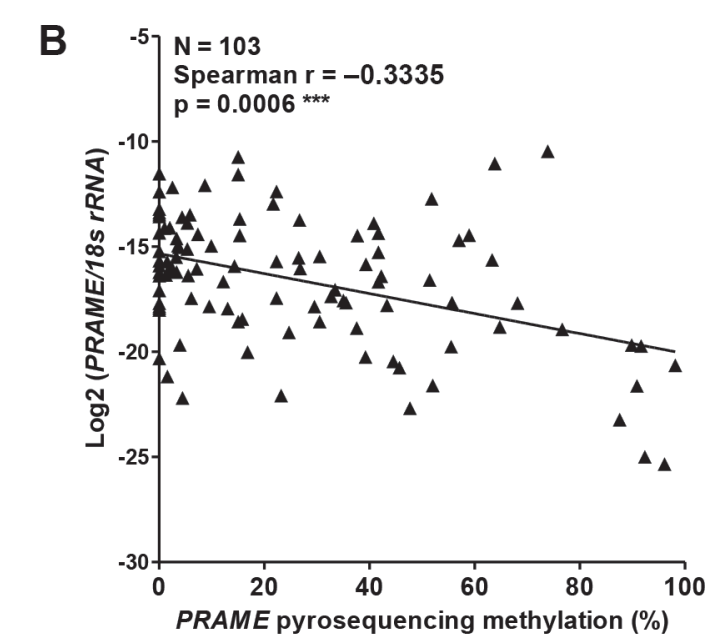

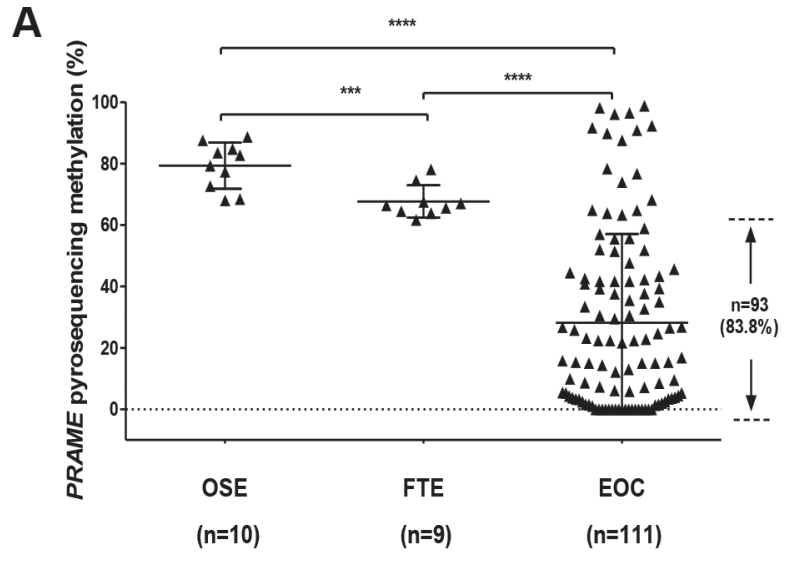

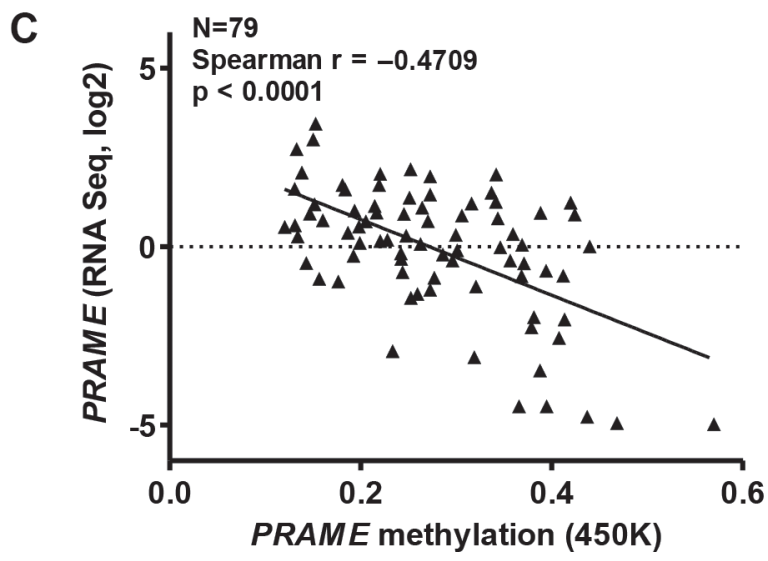

Figure 5: Sodium bisulfite pyrosequencing of $P R A M E 5^{\prime}$ region and $P R A M E$ mRNA expression. (A) Pyrosequencing methylation data for three CpGs (averaged) (see blue rectangle in Figure 4A) in OSE, FTE, and EOC. The proportion of EOC with $P R A M E$ methylation lower than all OSE and FTE samples is indicated. The two-tailed Mann-Whitney test $p$-value is indicated $(* * * P<0.001$; $* * * * P<0.0001$ ). (B) Association of PRAME methylation and expression. PRAME mRNA expression was measured by RT-qPCR and was normalized to $18 \mathrm{~s} r R N A$ expression. PRAME promoter methylation was measured by pyrosequencing. Spearman test results (two-tailed) are shown. (C) PRAME methylation and mRNA expression in ICGC data. Methylation was determined in primary HGSC tumors using Illumina $450 \mathrm{~K}$ arrays and PRAME mRNA expression was determined using RNAseq. The CpG sites measured by this assay are indicated by stars in Figure 4A. Spearman test results (two-tailed) are shown. 
IHC of normal tissues indicated that PRAME was strongly expressed in testis but weakly expressed in most normal tissues, as reported previously [6] (data not shown). EOC showed widespread but variable levels of PRAME expression, and the staining was mostly cytoplasmic. Examples of weak, moderate, and strong PRAME staining in EOC are shown in Figure 9A-9C. Within tumors cores, PRAME was expressed in the epithelial cells but not stroma. We calculated a weighted index of PRAME cytoplasmic staining (H-score, scale 0-300), for each tumor, as described in Methods. The distribution of H-scores clustered around 100, indicating that most EOC express PRAME, but do so at relatively low levels (Figure 9D). PRAME H-score directly correlated with PRAME mRNA expression and indirectly with PRAME methylation, but the latter was not statistically significant (Table 1). PRAME protein expression was not associated with EOC clinicopathology, including survival (Table 1). Sub-group analysis using only HGSC data also indicated no association with survival (Table 1).

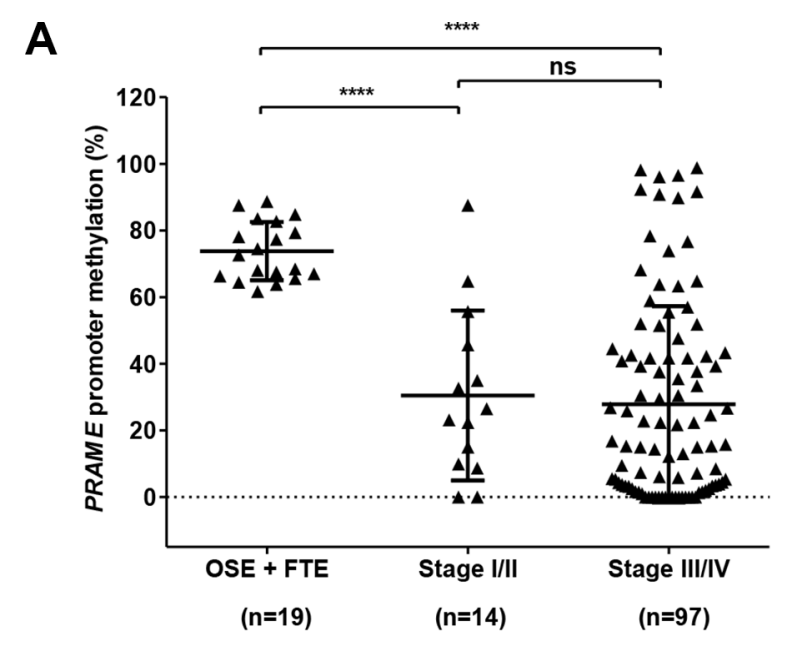

\section{$P R A M E$ expression and RA pathway alterations in EOC}

PRAME is a reported inhibitor of RA signaling [8, $24,25]$. In addition, the RA pathway is defective in many cancers, including EOC [49]. To test whether PRAME expression is associated with altered RA signaling in EOC and HGSC, we used Gene Set Enrichment Analysis (GSEA) to test the relationship between PRAME mRNA expression and RA-mediated gene expression in a large set of published EOC $(N=285)$ and HGSC $(N=218)$ expression data [50]. As shown in Figure 10, this analysis did not strongly support an association between PRAME expression and altered RA signaling in EOC or HGSC.

\section{DISCUSSION}

We show here that the CTA PRAME is frequently expressed in EOC and HGSC at the mRNA and protein levels, and demonstrate that promoter DNA

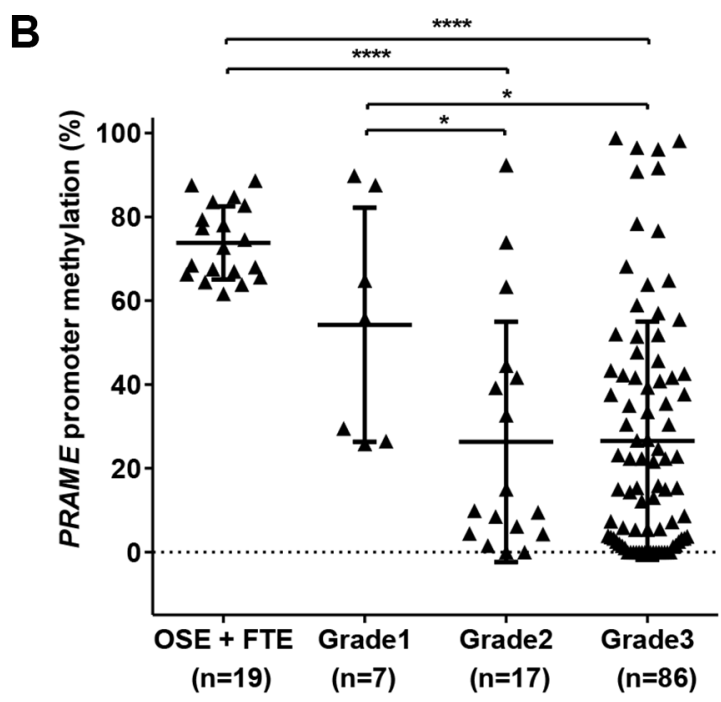

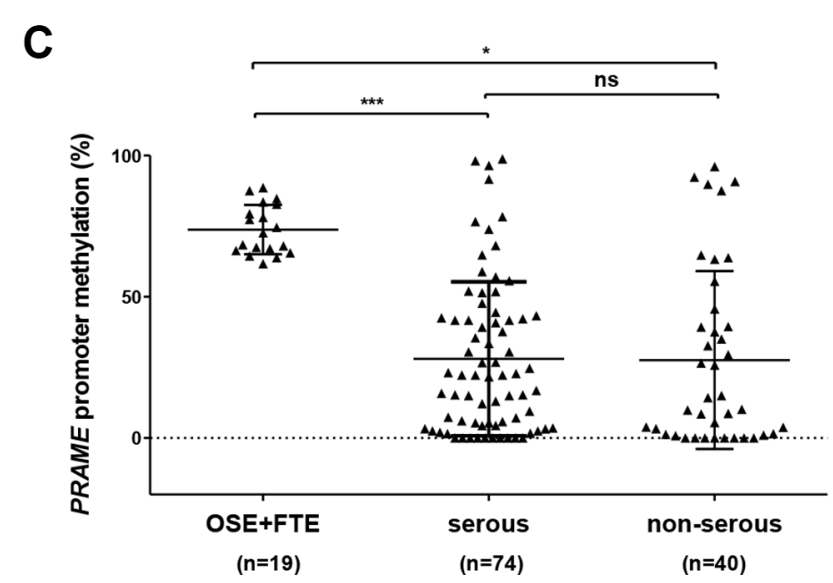

Figure 6: PRAME methylation and EOC stage, grade, and histology. (A-B) $P R A M E$ methylation was measured by pyrosequencing in OSE, FTE, and EOC, and data are shown as a function of EOC stage (A) and grade (B). (C) $P R A M E$ methylation in OSE + FTE, serous EOC, and non-serous EOC. The two-tailed Mann-Whitney test $p$-value is indicated $(* P<0.05 ; * * * P<0.001$; $* * * * P<0.0001 ;$ ns: not significant). 

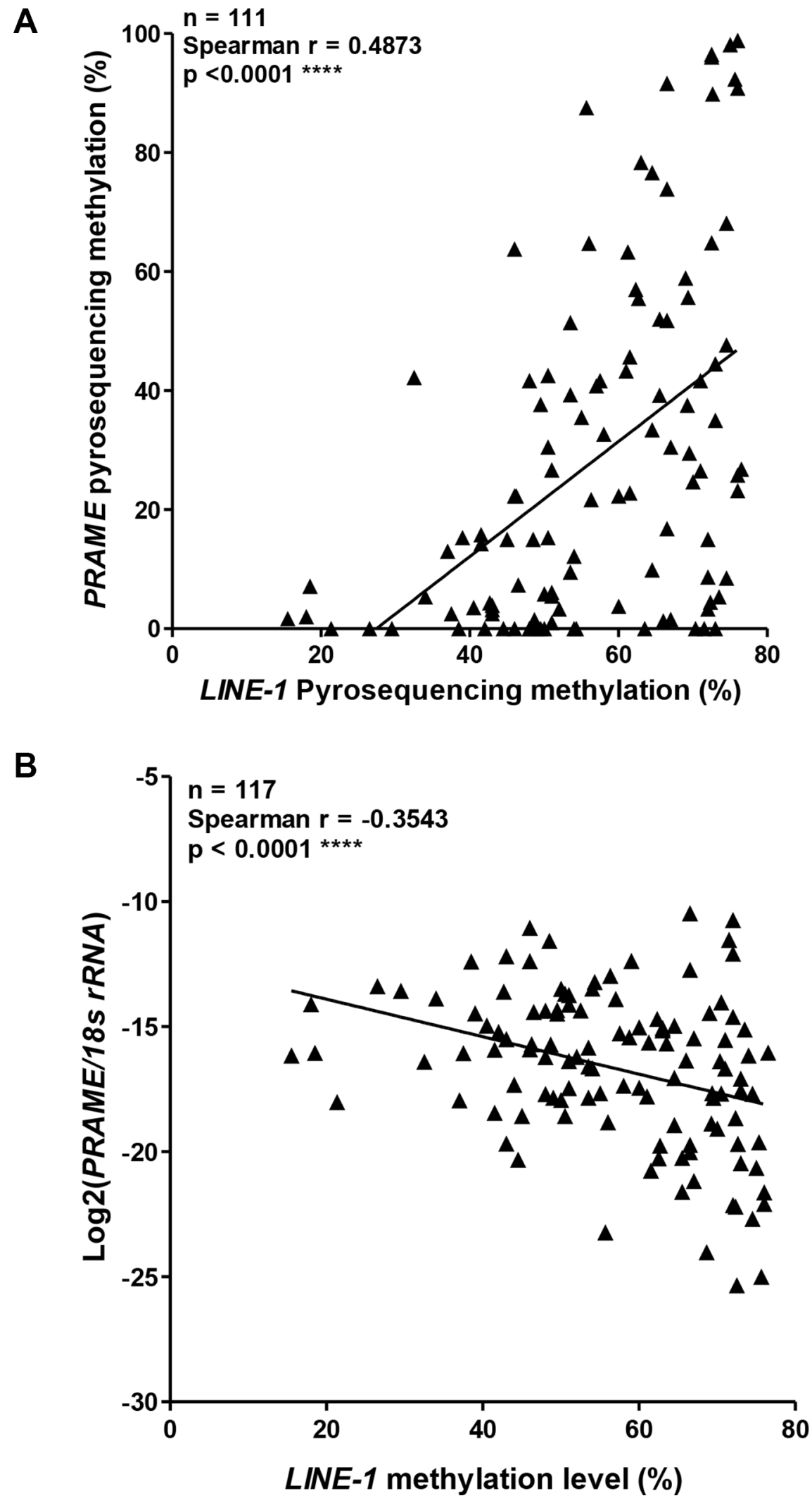

Figure 7: PRAME methylation and mRNA expression, and LINE-1 methylation in EOC. (A) $P R A M E$ promoter methylation compared to LINE-1 methylation in EOC. All methylation data were obtained by pyrosequencing. (B) PRAME mRNA expression and LINE-1 methylation in EOC. PRAME mRNA expression was determined by RT-qPCR and normalized to $18 s$ rRNA expression. LINE-1 methylation was determined by pyrosequencing. In both panels, Spearman test results (two-tailed) are shown. 


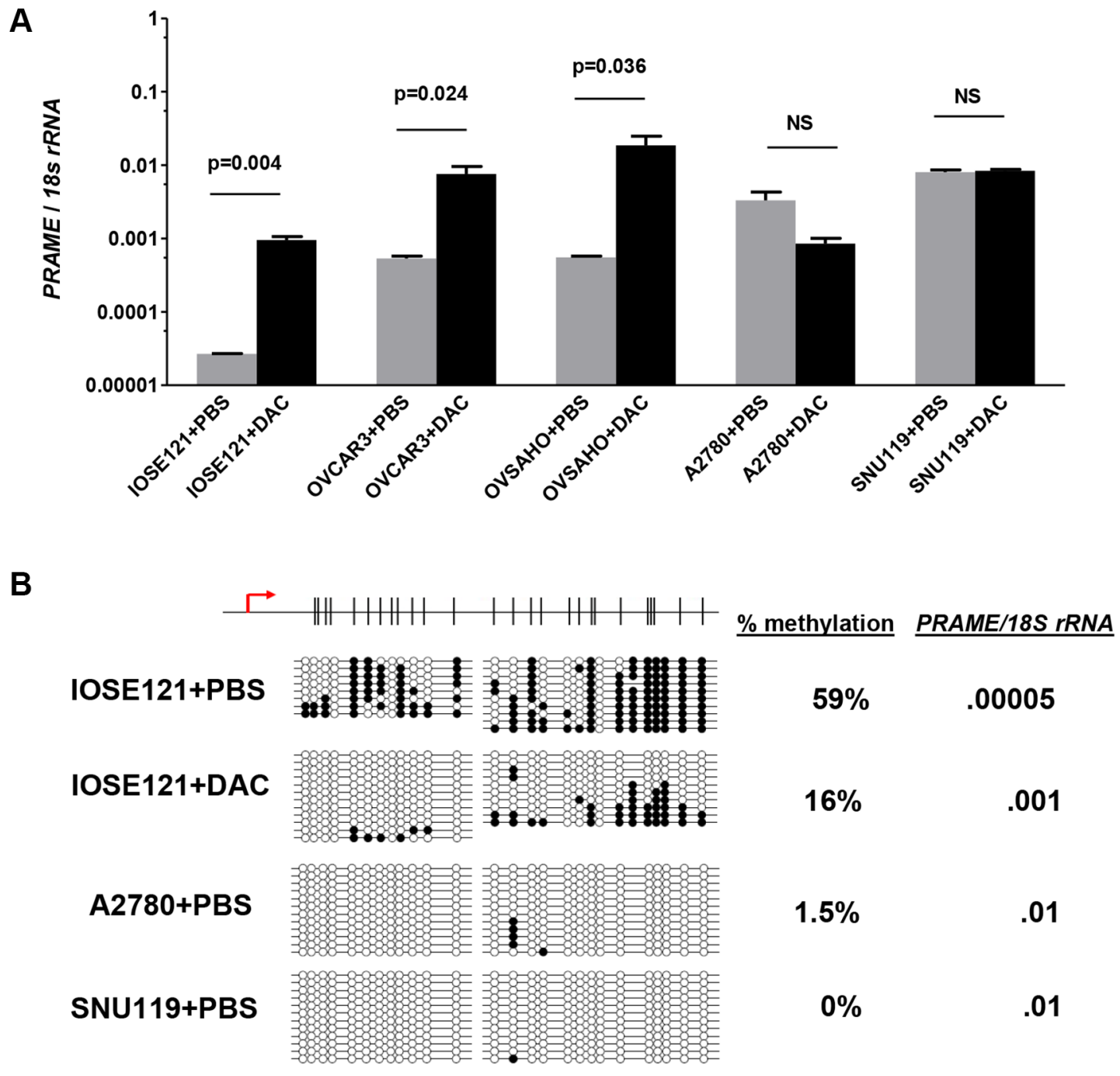

C

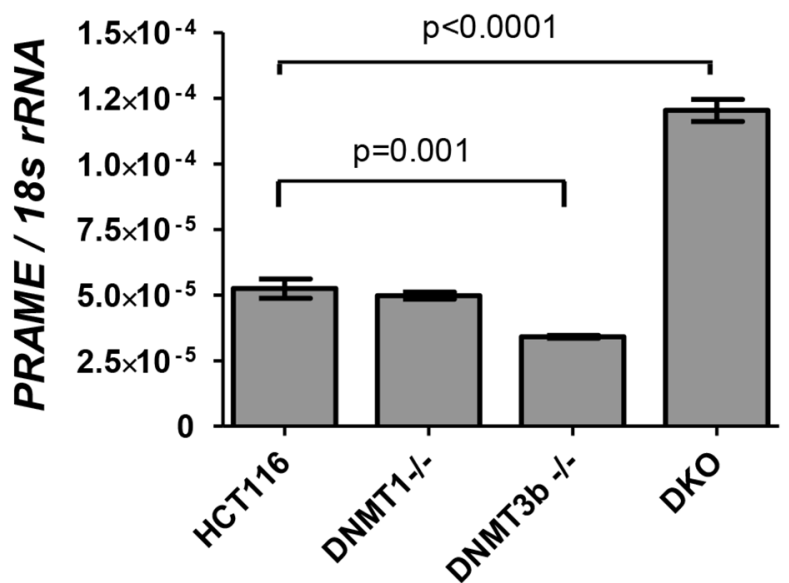

Figure 8: $P \boldsymbol{R} \boldsymbol{A M E}$ expression in decitabine (DAC)-treated and DNMT knockout cells. (A-B) IOSE121, OVCAR3, OVSAHO, A2780, and SNU119 cell lines were treated with vehicle (PBS) or $1 \mu \mathrm{M}$ decitabine (DAC) for 5 days as described in Methods. A. PRAME mRNA expression, determined by RT-qPCR. Data represent mean + SD. Paired two-tailed $t$-test results are shown. (B) Sodium bisulfite clonal sequencing results of the PRAME 5' region in IOSE121 cells after vehicle (PBS) or DAC treatment, and in A2780 and SNU119 cells after PBS treatment. The TSS and CpG map is shown at top. The percent methylation of all sequenced alleles, and the corresponding level of PRAME mRNA expression, is indicated at right. (C) PRAME mRNA expression was measured by RT-qPCR in wild-type HCT116 cells, DNMT1-/-, DNMT3b-/-, and double knockout (DKO) cells. Two-tailed unpaired $t$-test results are shown. 
hypomethylation is a key factor leading to its expression. Correlation analyses linked PRAME expression and promoter hypomethylation in primary tumors, and functional studies demonstrated that decitabine treatment and genetic disruption of DNMTs induced PRAME. PRAME expression and promoter hypomethylation were associated with $L I N E-1$ hypomethylation, suggesting that the global hypomethylation phenotype often observed in EOC is connected to PRAME regulation, analogous to other CTA genes [13, 41, 42, 51, 52].

In addition to DNA methylation, an epigenetic mechanism, we investigated whether CNA, a genetic mechanism, contributes to PRAME expression in HGSC. Although $P R A M E$ expression directly correlated with copy number, a minority of HGSC cases showed copy number gain or amplifications (16\%), and copy number loss was more a frequent alteration (64\%), suggesting that CNA makes a minor contributor to increased PRAME expression in HGSC. In contrast, PRAME promoter hypomethylation was a highly prevalent phenotype ( $85 \%$ of EOC). We recently reported that a different CTA gene, CT45, is also frequently hypomethylated in EOC, but rarely shows copy number gains [42]. These findings support the contention that epigenetic mechanisms are the major ones underlying increased CTA gene expression in EOC. Whether other epigenetic regulatory mechanisms described for CTAs, e.g. histone modifications and nucleosome occupancy $[51,53,54]$, also regulate $P R A M E$, is a topic of future interest.

PRAME expression and promoter hypomethylation were apparent in tumors of both early and late stage and of different grades, using samples comprised of diverse EOC sub-types. To test whether PRAME expression correlated with patient survival we used TCGA data, which is comprised only of HGSC. Somewhat surprisingly, this analysis indicated that PRAME expression correlated with improved OS and DFS. However, one caveat is that only for PRAME microarray data did this effect reach statistical significance, while RNAseq did not. A possible explanation for the improved survival seen with PRAME mRNA expression is that PRAME may be immunogenic in EOC patients, and this immunogenicity could drive
A

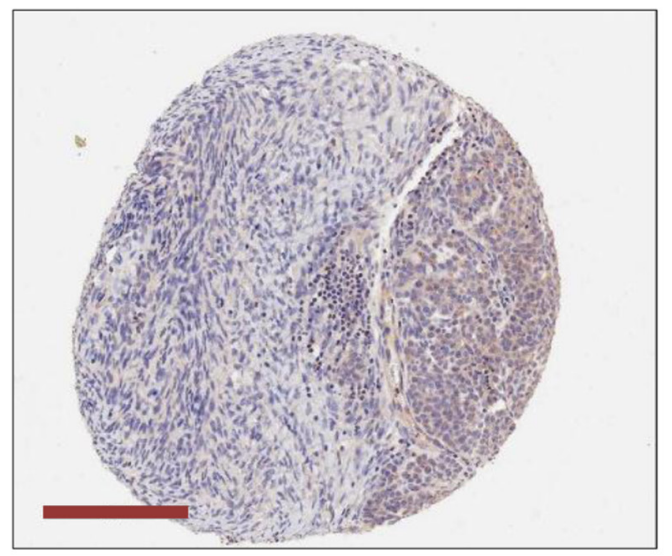

C

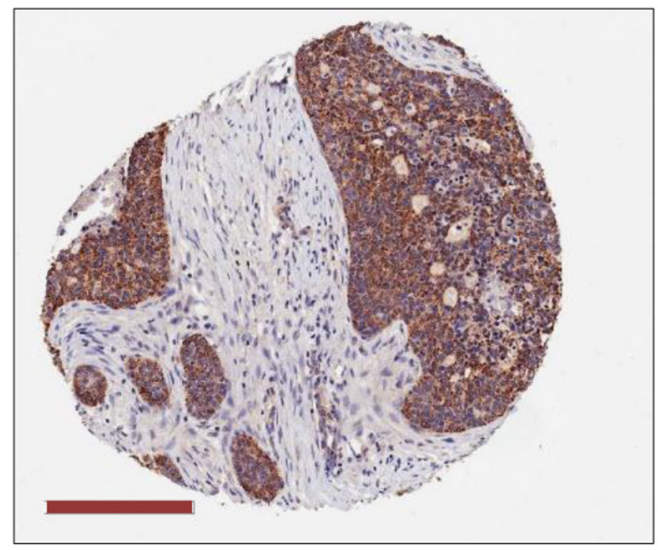

B

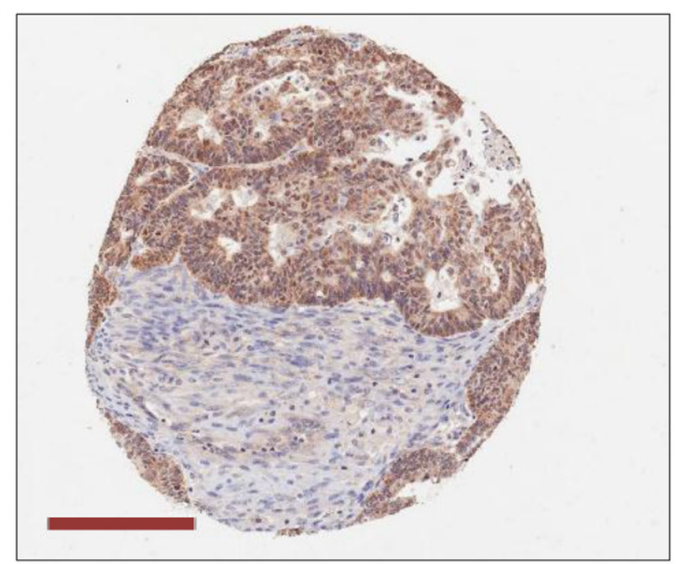

D

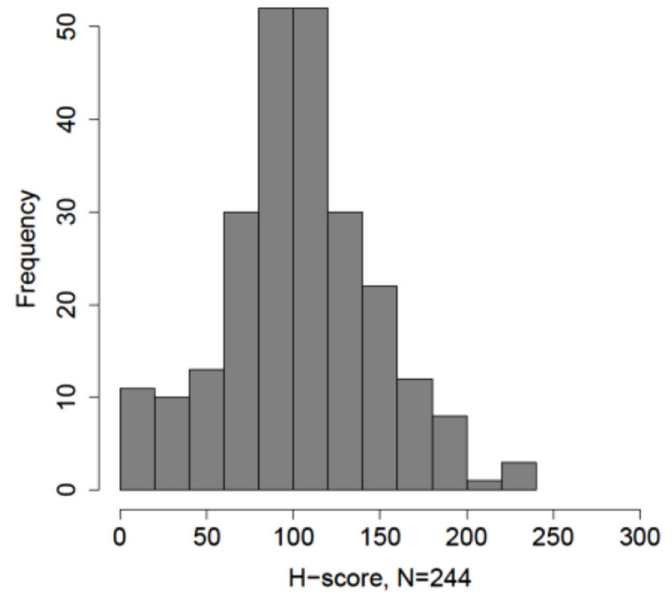

Figure 9: PRAME protein expression in EOC. PRAME protein expression was measured by IHC of EOC TMAs as described Methods. Examples of (A) weak, (B) moderate, and (C) strong PRAME staining is shown (magnification bars $=200 \mu M$ ). PRAME was expressed in the cytoplasm of epithelial cells, but not stroma. (D) A weighted index score for PRAME cytoplasmic staining (H-score, scale 0-300) for each tumor core was calculated as described in Methods. The distribution of H-scores in EOC samples $(N=244)$ is shown. Panels (A-C) are approximately equivalent to H-scores of 90, 185, and 290, respectively. 
Table 1: PRAME protein expression vs. molecular and clinical parameters in EOC

\begin{tabular}{|c|c|c|c|c|}
\hline & $\begin{array}{c}P R A M E m R N A / 18 S \\
r R N A(\mathrm{RT}-q \mathrm{PCR})\end{array}$ & \multicolumn{2}{|c|}{$P R A M E$ methylation (pyro) } & \\
\hline $\begin{array}{l}\text { PRAME protein } \\
\left.\text { (IHC H-Score }^{1}\right)\end{array}$ & $\begin{array}{c}0.287 \text { (Spearman) } \\
p=0.033 \\
N=55\end{array}$ & \multicolumn{2}{|c|}{$\begin{array}{c}-0.062 \text { (Spearman) } \\
p=0.686 \\
N=45\end{array}$} & \\
\hline $\operatorname{ALL~EOC~}(N=244)$ & & $\begin{array}{c}\text { Low H-Score } \\
\text { 2 } \\
N=122\end{array}$ & $\begin{array}{c}\text { High H-Score } \\
\qquad N=122\end{array}$ & $P$-value \\
\hline Age & & 62.5 & 64.0 & 0.390 \\
\hline Primary & $\begin{array}{c}\text { Multiple } \\
\text { Ovary } \\
\text { Primary Peritoneal } \\
\text { Fallopian Tube }\end{array}$ & $\begin{array}{c}1 \\
89 \\
27 \\
1\end{array}$ & $\begin{array}{c}4 \\
99 \\
15 \\
4\end{array}$ & 0.118 \\
\hline Stage & $\begin{array}{c}\text { IA, IB, IC, IIC, IIIB } \\
\text { IIIC, IV }\end{array}$ & $\begin{array}{l}25 \\
94\end{array}$ & $\begin{array}{l}25 \\
96\end{array}$ & 1.000 \\
\hline Grade & $\begin{array}{l}1,2 \\
3,4\end{array}$ & $\begin{array}{l}21 \\
95\end{array}$ & $\begin{array}{c}27 \\
100\end{array}$ & 0.439 \\
\hline Histology & $\begin{array}{c}\text { Serous } \\
\text { Clear Cell } \\
\text { Endometrioid } \\
\text { Mucinous } \\
\text { Other }\end{array}$ & $\begin{array}{c}81 \\
8 \\
7 \\
9 \\
17\end{array}$ & $\begin{array}{c}90 \\
4 \\
6 \\
3 \\
19\end{array}$ & 0.288 \\
\hline Debulking & $\begin{array}{l}\text { Optimal } \\
\text { Sub }\end{array}$ & $\begin{array}{c}48 \\
8\end{array}$ & $\begin{array}{l}50 \\
16\end{array}$ & 0.250 \\
\hline $\begin{array}{l}\text { Response to Primary } \\
\text { Treatment }\end{array}$ & $\begin{array}{l}\text { Complete } \\
\text { Otherwise }\end{array}$ & $\begin{array}{l}62 \\
41\end{array}$ & $\begin{array}{l}62 \\
31\end{array}$ & 0.429 \\
\hline Platinum Sensitivity & $\begin{array}{c}\text { Sensitive } \\
\text { Resistant/Refractory }\end{array}$ & $\begin{array}{l}52 \\
30\end{array}$ & $\begin{array}{l}51 \\
31\end{array}$ & 1.000 \\
\hline $\begin{array}{l}\text { PFS } \\
\text { OS }\end{array}$ & $\begin{array}{l}\text { Median Months } \\
(95 \% \mathrm{CI})\end{array}$ & $\begin{array}{l}18.5(13.7-24.3) \\
39.6(32.2-52.7)\end{array}$ & $\begin{array}{l}15.3(12.8-17.8) \\
49.7(39.8-67.0)\end{array}$ & $\begin{array}{l}0.227 \\
0.097\end{array}$ \\
\hline HGSC $(N=160)$ & & $\begin{array}{c}\text { Low H-Score } \\
N=76\end{array}$ & $\begin{array}{c}\text { High H-Score } \\
\quad N=84\end{array}$ & $P$-value \\
\hline $\begin{array}{l}\text { PFS } \\
\text { OS }\end{array}$ & $\begin{array}{l}\text { Median Months } \\
(95 \% \mathrm{CI})\end{array}$ & $\begin{array}{l}18.1(13.7-24.3) \\
51.1(41.8-77.1)\end{array}$ & $\begin{array}{l}15.3(12.8-17.9) \\
41.7(33.6-53.2)\end{array}$ & $\begin{array}{l}0.408 \\
0.227\end{array}$ \\
\hline
\end{tabular}

${ }^{1} \mathrm{H}$-score (range $=0$ to 300 ) is the extent of cytoplasmic immune staining, and $=3 \times \%$ strongly staining cytoplasm $+2 \times \%$ moderately staining cytoplasm $+\%$ weakly staining cytoplasm.

${ }^{2}$ Low and high H-score groups were split using the median H-score value, 88.3.

reduced disease burden $[6,10,21]$. This hypothesis should be tested using studies of PRAME specific antibodies and $\mathrm{T}$-cell responses, and by determining their relationship to patient survival.

Consistent with RT-qPCR analysis of PRAME, IHC analysis indicated that the PRAME protein is frequently expressed in EOC. However, PRAME protein expression levels were low to moderate in most tumors. This observation suggests that strategies to increase PRAME expression, for example by treatment with decitabine, could be useful in the context of PRAMEdirected immunotherapy $[12,23]$. Similar to PRAME mRNA expression, we did not observe a significant association between PRAME protein expression and
EOC clinicopathological measures, including stage and grade. While the correlation between PRAME mRNA and protein was statistically significant, it was relatively modest (Spearman $r=0.287$ ), suggesting that posttranscriptional mechanisms may be important regulators of PRAME protein levels.

Although PRAME was reported to be a negative regulator of RA signaling, our GSEA analysis in EOC or HGSC did not provide support this hypothesis. However, we were restricted to analyzing PRAME mRNA expression, which is not fully reflective of PRAME protein expression, as discussed above. Functional studies will be required to clarify whether PRAME plays a role in RA pathway regulation in EOC. 

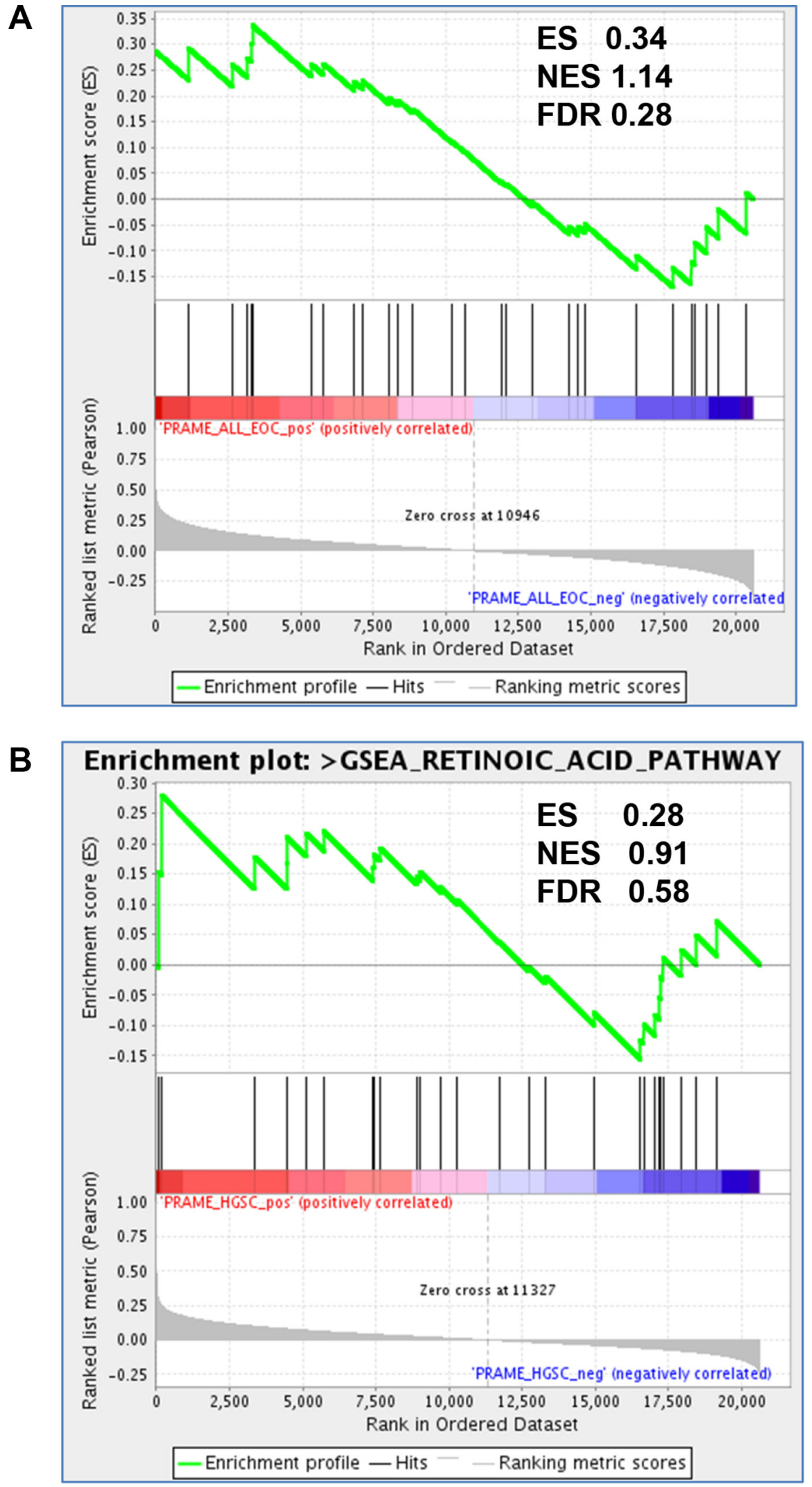

Figure 10: PRAME expression and RA pathway signatures in EOC. GSEA analysis of enrichment of RA pathway genes $(n=30)$ as a function of PRAME expression in (A) EOC $(N=285)$ and (B) HGSC $(N=218)$, using Affymetrix expression data from [50]. Enrichment score (ES), normalized enrichment score (NES), and false discovery rate $q$ values (FDR) are shown. Significant enrichment of RA pathway genes with PRAME expression was not observed. 
In summary, our study reveals that PRAME is frequently expressed in EOC and HGSC, and establishes it as a potential candidate for immunotherapy in ovarian cancer. The observed regulation of PRAME expression by DNA methylation, coupled with low protein expression in most tumors, raises the possibility that epigenetic modulators such as decitabine could be used to augment PRAME immunotherapy.

\section{MATERIALS AND METHODS}

\section{Human tissues}

We obtained NO, OSE, FTE, and EOC tissues using IRB-approved protocols at RPCI as described previously $[41,55]$. We prepared tissue extracts as described previously [13]. EOC tissues were estimated by pathology to contain $>80 \%$ neoplastic cells.

\section{Human cell lines}

We obtained and cultured SV40 Large-T antigenimmortalized normal human OSE cells, IOSE121, and EOC cell lines A2780 and OVCAR3 as described previously [13]. We obtained and cultured SNU119 and OVSAHO HGSC cells as described previously [39]. We obtained HCT116 wild-type, HCT116 DNMT1-/-, HCT116 DNMT3b-/-, and HCT116 DNMT1-/-, 3b-/(DKO) cells from Dr. Bert Vogelstein [47], and cultured as described previously [48].

\section{DNA and RNA extractions}

We isolated genomic DNA (gDNA) using the Puregene Kit A (Qiagen), and purified total RNA using TRIzol $^{\circledR}$ (Invitrogen).

\section{Decitabine (DAC) treatment}

We obtained decitabine from Sigma. We treated cells at $\sim 70 \%$ confluence with $1 \mu \mathrm{M}$ DAC (day 0 ), passaged cells at day 2 , re-treated with $1 \mu \mathrm{M}$ DAC at day 3 , and harvested cells for RNA and gDNA extracts at day 5 .

\section{Reverse transcriptase quantitative PCR (RT- qPCR)}

We processed RNA using the DNA-free kit (Ambion), and performed cDNA synthesis using the iScript cDNA Synthesis Kit (BioRad). We measured PRAME expression by qPCR using a BioRad CFX Connect system and the Sybr green method. We prepared standard curves using a mixture of cDNA from EOC cell lines, and normalized PRAME mRNA expression to $18 s \quad r R N A$. Primer sequences are provided in Supplementary Table 1.

\section{EOC TMA and PRAME IHC}

EOC TMA were described previously $[42,56]$. TMA sections were cut to $4 \mu \mathrm{m}$, placed on charged slides, and dried at $60^{\circ} \mathrm{C}$ for one hour. Slides were cooled to room temperature, de-paraffinized in three changes of xylene, and rehydrated using graded alcohols. For antigen retrieval, slides were heated in a steamer for 40 minutes in EDTA buffer, $\mathrm{pH}=8$, (Lab Vision), followed by a 20-minute cool down. Endogenous peroxidase was quenched with aqueous $0.3 \% \mathrm{H}_{2} \mathrm{O}_{2}$ for 10 minutes and washed with PBS/T. Slides were loaded on a DAKO autostainer (Dako) and serum-free protein block was applied for 5 minutes, blown off, and then PRAME primary antibody (Sigma, catalog no. HPA045153) was applied at $1.3 \mu \mathrm{g} / \mathrm{ml}$ for one hour. A matched isotype antibody was applied to a replicate slide, in place of primary antibody, as a negative control. The EnVision+ horseradish peroxidase system (Dako) and DAB chromogen were used for visualization. Slides were counterstained with hematoxylin, dehydrated, cleared and cover slipped.

\section{Aperio slide scanning and IHC image analysis}

TMA slides were digitally scanned using Aperio Scanscope (Aperio Technologies) with 20x bright-field microscopy. These images are then accessible using Spectrum (Aperio Technologies). Once slides are scanned, Aperio ImageScope version 11.2.0.780 was used to view images for image analysis. Images were examined for quality and were amended as necessary. An annotation layer was created for each TMA core. Tumor regions were identified and annotated to appropriately represent the heterogeneity of staining for image analysis. The Aperio platform was used to develop quantitative image analysis algorithm macros for quantification of IHC. The cytoplasmic algorithm was modified to detect and quantify the positive DAB staining cells. The intensity for the positive stain was divided into four score values, 0 -none, 1+- weak, 2+-moderate, and 3+-strong. For each cytoplasm threshold, the percentage of cells having staining in the cytoplasm was provided, and the overall percentage of positive cells and average intensity score were calculated for each layer. In addition, the algorithm provided an $\mathrm{H}$-Score. The $\mathrm{H}$-score is a cytoplasmic intensity score derived from the average intensity of the staining of the cytoplasm, according to the threshold intervals set in the algorithm macro. $\mathrm{H}$-score $=1 *(\% 1+)+2 *(\% 2+)+$ $3 *(\% 3+)$, with the score between 0 and 300 , where 300 represents $100 \%$ of cells being $3+$. PRAME H-scores were averaged over $1-6$ slides for each patient $(N=244)$.

\section{DNA methylation analyses}

We used sodium bisulfite clonal sequencing and sodium bisulfite pyrosequencing to determine the DNA methylation status of the PRAME 5' region $[44,57]$. 
We performed bisulfite conversions using the EZ DNA Methylation Kit (Zymo Research) and designed bisulfite sequencing primers using MethPrimer. We determined LINE-1 repetitive element DNA methylation using bisulfite pyrosequencing as described previously [40]. Primer sequences are reported in Supplementary Table 1.

\section{PRAME mRNA expression and HGSC survival}

We retrieved TCGA HGSC PRAME mRNA expression datasets [Affymetrix U133 microarray $(N=576)$, Agilent microarray $(N=561)$, and RNAseq $(\mathrm{N}=307)]$ and patient survival data using cBioPortal [36, 37]. We performed survival analyses using Graphpad Prism.

\section{PRAME protein expression vs. EOC clinicopathology}

Overall Survival (OS) was defined as the time between the date of diagnosis and death. Patients who were alive at the time of analysis were censored at the date of last follow up. Progression-free survival (PFS) was defined as the time between the date of surgery and disease recurrence. Patients who were alive and disease-free were censored at the date of last follow-up and median survival times were estimated from the Kaplan-Meier curve. Association between PRAME H-score and clinical parameters was tested with a combination of chi-square and $t$-tests as appropriate; all tests were two-sided.

\section{$P R A M E$ copy number and $m R N A$ expression in TCGA HGSC data}

We retrieved TCGA copy number data for HGSC and other tumor types from cBioPortal [36, 37], and obtained GISTIC putative copy-number alterations using Onco Query Language. We obtained PRAME mRNA expression data (RNA-seq, $N=300$; Affymetrix U133 microarray, $N=556$ ) from cBioPortal.

\section{PRAME methylation and mRNA expression from International Cancer Genome Consortium (ICGC) primary tumor HGSC data}

The Ovarian Cancer - Australia (OV-AU) DNA methylation (Illumina $450 \mathrm{~K}$ methylation) and gene expression (Illumina RNAseq) datasets, both version 2015-07-15, were downloaded from UCSC Xena (https:// genome-cancer.soe.ucsc.edu/proj/site/xena/heatmap/). Statistical analysis was performed with Graphpad prism. This data set has been described [5].

\section{GSEA analysis for RA pathway signatures}

We performed GSEA http://www.broadinstitute. org/gsea/index.jsp) to test for enrichment of RA pathway network genes (http://software.broadinstitute.org/
gsea/msigdb/geneset_page.jsp?geneSetName $=$ PID RETINOIC_ACID_PATHWAY, $N=30$ genes) with PRAME expression in EOC $(N=285)$ or HGSC $(N=218)$. We used a continuous phenotype model, based on PRAME expression data obtained from Affymetrix U133 Plus 2 arrays (GEO accession GSE9899) [50].

\section{Statistical analyses of molecular data}

We used Graphpad Prism for standard statistical analyses to compare molecular parameters between sample groups. The statistical test used and $p$-values are provided in the figures and figure legends.

\section{ACKNOWLEDGMENTS}

We thank Nelly Auersperg for IOSE-121 cells, Bert Vogelstein for HCT116 and DNMT knockout cell derivatives, and Austin Miller, Stacey Akers, and Linda Chee for assistance. We thank David Jones (Oklahoma Medical Research Foundation) for input.

\section{CONFLICTS OF INTEREST}

The authors have no conflicts of interest to declare.

\section{FUNDING}

ARK was supported by the Otis Glebe Medical Research Foundation, the Betty J. and Charles D. McKinsey Ovarian Cancer Research Fund, and The Fred \& Pamela Buffett Cancer Center (NIH P30 CA036727). CJB was supported by NIH T32CA009476 and a UNMC Program of Excellence Assistantship. KO was supported by a Roswell Park Alliance Foundation grant, NIH grants 1R01CA158318, P30CA016056, and RPCI-UPCI Ovarian Cancer SPORE P50CA159981.

\section{REFERENCES}

1. Ferlay J, Shin HR, Bray F, Forman D, Mathers C, Parkin DM. Estimates of worldwide burden of cancer in 2008: GLOBOCAN 2008. International journal of cancer. 2010; 127:2893-2917.

2. Siegel RL, Miller KD, Jemal A. Cancer statistics, 2015. CA Cancer J Clin. 2015; 65:5-29.

3. Prat J. Staging classification for cancer of the ovary, fallopian tube, and peritoneum. Int $\mathrm{J}$ Gynaecol Obstet. 2014; $124: 1-5$.

4. Integrated genomic analyses of ovarian carcinoma. Nature. 2011; 474:609-615.

5. Patch AM, Christie EL, Etemadmoghadam D, Garsed DW, George J, Fereday S, Nones K, Cowin P, Alsop K, Bailey PJ, Kassahn KS, Newell F, Quinn MC, et al. Wholegenome characterization of chemoresistant ovarian cancer. Nature. 2015; 521:489-494. 
6. Ikeda H, Lethe B, Lehmann F, van Baren N, Baurain JF, de Smet C, Chambost H, Vitale M, Moretta A, Boon T, Coulie PG. Characterization of an antigen that is recognized on a melanoma showing partial HLA loss by CTL expressing an NK inhibitory receptor. Immunity. 1997; 6:199-208.

7. Wadelin F, Fulton J, McEwan PA, Spriggs KA, Emsley J, Heery DM. Leucine-rich repeat protein PRAME: expression, potential functions and clinical implications for leukaemia. Molecular cancer. 2010; 9:226.

8. Redner RL. PRAMEing a picture of differentiation therapy for AML? Clinical cancer research. 2013; 19:2277-2279.

9. Gerard C, Baudson N, Ory T, Segal L, Louahed J. A Comprehensive Preclinical Model Evaluating the Recombinant PRAME Antigen Combined With the AS15 Immunostimulant to Fight Against PRAME-expressing Tumors. Journal of immunotherapy. 2015; 38:311-320.

10. Spel L, Boelens JJ, van der Steen DM, Blokland NJ, van Noesel MM, Molenaar JJ, Heemskerk MH, Boes M, Nierkens S. Natural killer cells facilitate PRAME-specific T-cell reactivity against neuroblastoma. Oncotarget. 2015; 6:35770-35781. doi: 10.18632/oncotarget.5657.

11. Hermesa N, Kewitza S, Staege MS. Preferentially Expressed Antigen in Melanoma (PRAME) and the PRAME family of Leucine-Rich Repeat Proteins". Current cancer drug targets. 2015.

12. Akers SN, Odunsi K, Karpf AR. Regulation of cancer germline antigen gene expression: implications for cancer immunotherapy. Future oncology. 2010; 6:717-732.

13. Woloszynska-Read A, James SR, Link PA, Yu J, Odunsi K, Karpf AR. DNA methylation-dependent regulation of BORIS/CTCFL expression in ovarian cancer. Cancer Immun. 2007; 7:21.

14. Ortmann CA, Eisele L, Nuckel H, Klein-Hitpass L, Fuhrer A, Duhrsen U, Zeschnigk M. Aberrant hypomethylation of the cancer-testis antigen PRAME correlates with PRAME expression in acute myeloid leukemia. Annals of hematology. 2008; 87:809-818.

15. Qian J, Zhu ZH, Lin J, Ming Yao DM, Li Y, Yang J, Wang CZ. Hypomethylation of PRAME promoter is associated with poor prognosis in myelodysplastic syndrome. British journal of haematology. 2011; 154:153-155.

16. Atanackovic D, Luetkens T, Kloth B, Fuchs G, Cao Y, Hildebrandt Y, Meyer S, Bartels K, Reinhard H, Lajmi N, Hegewisch-Becker S, Schilling G, Platzbecker U, et al. Cancer-testis antigen expression and its epigenetic modulation in acute myeloid leukemia. American journal of hematology. 2011; 86:918-922.

17. Gutierrez-Cosio S, de la Rica L, Ballestar E, Santamaria C, Sanchez-Abarca LI, Caballero-Velazquez T, Blanco B, Calderon C, Herrero-Sanchez C, Carrancio S, Ciudad L, Canizo C, San Miguel JF, et al. Epigenetic regulation of PRAME in acute myeloid leukemia is different compared to CD34+ cells from healthy donors: effect of 5-AZA treatment. Leukemia research. 2012; 36:895-899.
18. Roman-Gomez J, Jimenez-Velasco A, Agirre $\mathrm{X}$, Castillejo JA, Navarro G, Jose-Eneriz ES, Garate L, Cordeu L, Cervantes F, Prosper F, Heiniger A, Torres A. Epigenetic regulation of PRAME gene in chronic myeloid leukemia. Leukemia research. 2007; 31:1521-1528.

19. Sigalotti L, Fratta E, Coral S, Tanzarella S, Danielli R, Colizzi F, Fonsatti E, Traversari C, Altomonte M, Maio M. Intratumor heterogeneity of cancer/testis antigens expression in human cutaneous melanoma is methylation-regulated and functionally reverted by 5 -aza2'-deoxycytidine. Cancer research. 2004; 64:9167-9171.

20. Pollack SM, Li Y, Blaisdell MJ, Farrar EA, Chou J, Hoch BL, Loggers ET, Rodler E, Eary JF, Conrad EU, 3rd, Jones RL, Yee C. NYESO-1/LAGE-1s and PRAME are targets for antigen specific $\mathrm{T}$ cells in chondrosarcoma following treatment with 5-Aza-2-deoxycitabine. PloS one. 2012; 7:e32165.

21. Yao Y, Zhou J, Wang L, Gao X, Ning Q, Jiang M, Wang J, Yu L. Increased PRAME-specific CTL killing of acute myeloid leukemia cells by either a novel histone deacetylase inhibitor chidamide alone or combined treatment with decitabine. PloS one. 2013; 8:e70522.

22. Yan M, Himoudi N, Basu BP, Wallace R, Poon E, Adams S, Hasan F, Xue SA, Wilson N, Dalgleish A, Williams O, Anderson J. Increased PRAME antigen-specific killing of malignant cell lines by low avidity CTL clones, following treatment with 5-Aza-2'-Deoxycytidine. Cancer immunology, immunotherapy. 2011; 60:1243-1255.

23. Odunsi K, Matsuzaki J, James SR, Mhawech-Fauceglia P, Tsuji T, Miller A, Zhang W, Akers SN, Griffiths EA, Miliotto A, Beck A, Batt CA, Ritter G, et al. Epigenetic potentiation of NY-ESO-1 vaccine therapy in human ovarian cancer. Cancer immunology research. 2014; 2:37-49.

24. Epping MT, Wang L, Edel MJ, Carlee L, Hernandez M, Bernards R. The human tumor antigen PRAME is a dominant repressor of retinoic acid receptor signaling. Cell. $2005 ; 122: 835-847$.

25. Bullinger L, Schlenk RF, Gotz M, Botzenhardt U, Hofmann S, Russ AC, Babiak A, Zhang L, Schneider V, Dohner K, Schmitt M, Dohner H, Greiner J. PRAMEinduced inhibition of retinoic acid receptor signalingmediated differentiation - a possible target for ATRA response in AML without $\mathrm{t}(15 ; 17)$. Clinical cancer research. 2013; 19:2562-2571.

26. Kewitz S, Staege MS. Knock-down of PRAME increases retinoic acid signaling and cytotoxic drug sensitivity of Hodgkin lymphoma cells. PloS one. 2013; 8:e55897.

27. Xu Y, Yue Q, Wei H, Pan G. PRAME induces apoptosis and inhibits proliferation of leukemic cells in vitro and in vivo. International journal of clinical and experimental pathology. 2015; 8:14549-14555.

28. Yan H, Zhao RM, Wang ZJ, Zhao FR, Wang SL. Knockdown of PRAME enhances adriamycin-induced 
apoptosis in chronic myeloid leukemia cells. European review for medical and pharmacological sciences. 2015; 19:4827-4834.

29. Goodison S, Urquidi V. The cancer testis antigen PRAME as a biomarker for solid tumor cancer management. Biomarkers in medicine. 2012; 6:629-632.

30. Field MG, Decatur CL, Kurtenbach S, Gezgin G, van der Velden PA, Jager MJ, Kozak KN, Harbour JW. PRAME as an Independent Biomarker for Metastasis in Uveal Melanoma. Clinical cancer research. 2016; 22:1234-1242.

31. Ercolak V, Paydas S, Bagir E, Ergin M, Seydaoglu G, Celik H, Yavuz B, Tanriverdi K, Gunaldi M, Afsar CU, Duman BB. PRAME Expression and Its Clinical Relevance in Hodgkin's Lymphoma. Acta haematologica. 2015; 134:199-207.

32. Brenne K, Nymoen DA, Reich R, Davidson B. PRAME (preferentially expressed antigen of melanoma) is a novel marker for differentiating serous carcinoma from malignant mesothelioma. American journal of clinical pathology. 2012; 137:240-247.

33. Partheen K, Levan K, Osterberg L, Horvath G. Expression analysis of stage III serous ovarian adenocarcinoma distinguishes a sub-group of survivors. European journal of cancer. 2006; 42:2846-2854.

34. Partheen K, Levan K, Osterberg L, Claesson I, Sundfeldt K, Horvath $\mathrm{G}$. External validation suggests Integrin beta 3 as prognostic biomarker in serous ovarian adenocarcinomas. BMC cancer. 2009; 9:336.

35. Partheen K, Levan K, Osterberg L, Claesson I, Fallenius G, Sundfeldt K, Horvath G. Four potential biomarkers as prognostic factors in stage III serous ovarian adenocarcinomas. International journal of cancer. 2008; 123:2130-2137.

36. Cerami E, Gao J, Dogrusoz U, Gross BE, Sumer SO, Aksoy BA, Jacobsen A, Byrne CJ, Heuer ML, Larsson E, Antipin Y, Reva B, Goldberg AP, et al. The cBio cancer genomics portal: an open platform for exploring multidimensional cancer genomics data. Cancer discovery. 2012; 2:401-404.

37. Gao J, Aksoy BA, Dogrusoz U, Dresdner G, Gross B, Sumer SO, Sun Y, Jacobsen A, Sinha R, Larsson E, Cerami E, Sander C, Schultz N. Integrative analysis of complex cancer genomics and clinical profiles using the cBioPortal. Science signaling. 2013; 6:p11.

38. Ciriello G, Miller ML, Aksoy BA, Senbabaoglu Y, Schultz N, Sander C. Emerging landscape of oncogenic signatures across human cancers. Nature genetics. 2013; 45:1127-1133.

39. Barger CJ, Zhang W, Hillman J, Stablewski AB, Higgins MJ, Vanderhyden BC, Odunsi K, Karpf AR. Genetic determinants of FOXM1 overexpression in epithelial ovarian cancer and functional contribution to cell cycle progression. Oncotarget. 2015; 6:27613-27627. doi: 10.18632/oncotarget.4546.

40. Woloszynska-Read A, Mhawech-Fauceglia P, Yu J, Odunsi K, Karpf AR. Intertumor and intratumor NY-ESO-1 expression heterogeneity is associated with promoterspecific and global DNA methylation status in ovarian cancer. Clinical cancer research. 2008; 14:3283-3290.

41. Woloszynska-Read A, Zhang W, Yu J, Link PA, MhawechFauceglia P, Collamat G, Akers SN, Ostler KR, Godley LA, Odunsi K, Karpf AR. Coordinated cancer germline antigen promoter and global DNA hypomethylation in ovarian cancer: association with the BORIS/CTCF expression ratio and advanced stage. Clinical cancer research. 2011; 17:2170-2180.

42. Zhang W, Barger CJ, Link PA, Mhawech-Fauceglia P, Miller A, Akers SN, Odunsi K, Karpf AR. DNA hypomethylation-mediated activation of Cancer/Testis Antigen 45 (CT45) genes is associated with disease progression and reduced survival in epithelial ovarian cancer. Epigenetics. 2015; 10:736-748.

43. Gardiner-Garden M, Frommer M. CpG islands in vertebrate genomes. Journal of molecular biology. 1987; 196:261-282.

44. Dupont JM, Tost J, Jammes H, Gut IG. De novo quantitative bisulfite sequencing using the pyrosequencing technology. Analytical biochemistry. 2004; 333:119-127.

45. De Smet C, De Backer O, Faraoni I, Lurquin C, Brasseur F, Boon T. The activation of human gene MAGE-1 in tumor cells is correlated with genome-wide demethylation. Proceedings of the National Academy of Sciences of the United States of America. 1996; 93:7149-7153.

46. Egger G, Liang G, Aparicio A, Jones PA. Epigenetics in human disease and prospects for epigenetic therapy. Nature. 2004; 429:457-463.

47. Rhee I, Bachman KE, Park BH, Jair KW, Yen RW, Schuebel KE, Cui H, Feinberg AP, Lengauer C, Kinzler KW, Baylin SB, Vogelstein B. DNMT1 and DNMT3b cooperate to silence genes in human cancer cells. Nature. 2002; 416:552-556.

48. Song L, James SR, Kazim L, Karpf AR. Specific method for the determination of genomic DNA methylation by liquid chromatography-electrospray ionization tandem mass spectrometry. Anal Chem. 2005; 77:504-510.

49. Doldo E, Costanza G, Agostinelli S, Tarquini C, Ferlosio A, Arcuri G, Passeri D, Scioli MG, Orlandi A. Vitamin A, cancer treatment and prevention: the new role of cellular retinol binding proteins. BioMed research international. 2015; 2015:624627.

50. Tothill RW, Tinker AV, George J, Brown R, Fox SB, Lade S, Johnson DS, Trivett MK, Etemadmoghadam D, Locandro B, Traficante N, Fereday S, Hung JA, et al. Novel molecular subtypes of serous and endometrioid ovarian cancer linked to clinical outcome. Clinical cancer research. 2008; 14:5198-5208.

51. James SR, Cedeno CD, Sharma A, Zhang W, Mohler JL, Odunsi K, Wilson EM, Karpf AR. DNA methylation and nucleosome occupancy regulate the cancer germline antigen gene MAGEA11. Epigenetics. 2013; 8:849-863. 
52. Link PA, Zhang W, Odunsi K, Karpf AR. BORIS/CTCFL mRNA isoform expression and epigenetic regulation in epithelial ovarian cancer. Cancer Immun. 2013; 13:6.

53. Link PA, Gangisetty O, James SR, Woloszynska-Read A, Tachibana M, Shinkai Y, Karpf AR. Distinct roles for histone methyltransferases G9a and GLP in cancer germline antigen gene regulation in human cancer cells and murine embryonic stem cells. Mol Cancer Res. 2009; 7:851-862.

54. James SR, Link PA, Karpf AR. Epigenetic regulation of $\mathrm{X}$-linked cancer/germline antigen genes by DNMT1 and DNMT3b. Oncogene. 2006; 25:6975-6985.

55. Akers SN, Moysich K, Zhang W, Collamat Lai G, Miller A, Lele S, Odunsi K, Karpf AR. LINE1 and Alu repetitive element DNA methylation in tumors and white blood cells from epithelial ovarian cancer patients. Gynecologic oncology. 2014; 132:462-467.
56. Chen YT, Hsu M, Lee P, Shin SJ, Mhawech-Fauceglia P, Odunsi K, Altorki NK, Song CJ, Jin BQ, Simpson AJ, Old LJ. Cancer/testis antigen CT45: analysis of mRNA and protein expression in human cancer. International journal of cancer. 2009; 124:2893-2898.

57. Clark SJ, Harrison J, Paul CL, Frommer M. High sensitivity mapping of methylated cytosines. Nucleic acids research. 1994; 22:2990-2997. 